\title{
The location of hydrogen atoms in crystalline ionic hydrates
}

\author{
By M. F. C. LADD \\ Department of Chemical Physics, University of Surrey*
}

(Received January 13, 1967)

\begin{abstract}
Auszug
Die Bestimmung der Orte von Wasserstoffatomen in Ionenhydraten werden durch Rechnungen auf Grundlage der Gitterenergie diskutiert und die Ergebnisse für zwei Hydrate, $\mathrm{BaCl}_{2} \cdot 2 \mathrm{H}_{2} \mathrm{O}$ und $\mathrm{NaBr} \cdot 2 \mathrm{H}_{2} \mathrm{O}$, mitgeteilt.
\end{abstract}

\section{Abstract}

The location of hydrogen atoms in ionic hydrates by calculations based upon energetics of crystal structures is discussed. Results are presented for two hydrates, $\mathrm{BaCl}_{2} \cdot 2 \mathrm{H}_{2} \mathrm{O}$ and $\mathrm{NaBr} \cdot 2 \mathrm{H}_{2} \mathrm{O}$.

\section{Introduction}

Thermodynamic calculations of lattice energies of ionic hydrates have been described recently by LADD and LEE (1965). A consideration of some of the factors involved in the energetics of hydrate formation focussed attention upon the location of hydrogen atoms in crystalline hydrates.

The principal methods used to determine the positions of hydrogen atoms are, in order of preference, neutron-diffraction measurements and proton magnetic resonance measurements. The second of these methods requires assumptions to be made about the probable direction of $\mathrm{O}-\mathrm{H}$ vectors or about general atomic packing, since only the $\mathrm{H}-\mathrm{H}$ vector is located experimentally.

From a neutron-diffraction study of barium-chloride dihydrate, Padmanabhan, Busing and Levy (1963) obtained hydrogen-atom positions appreciably different from those obtained by SILVIDI and MCGRaTH (1960) on the basis of proton magnetic resonance studies. The present paper is concerned with an alternative method for deter-

* London, S. W. 11. 
mining the positions of hydrogen atoms, which, in the case of bariumchloride dihydrate, is shown to lead to coordinates in good general agreement with those obtained by the neutron-diffraction study.

\section{Method}

The coordinates $x^{\prime}, y^{\prime}, z^{\prime}$ of the positive end of the dipole of the water molecule in an ionic hydrate have been located by a vectorial summation of weighted electrical field strengths around the oxygen atom in the water molecule, using Equation (1):

$$
x^{\prime}=\sum_{i}\left(-Z_{i} x_{i} / d_{i}^{2}\right)
$$

$x_{i}$ is the $x$ coordinate of the $i$ th ion, distant $d_{i}$ from the oxygen atom; $Z_{i}$ is its charge, including the sign. For the ions in the crystal, the usual charges were used. With the water molecule, the effective charges on the atoms were deduced from the dipole moment of water, $1.84 \cdot 10^{-18}$ e.s.u., leading to the values $z_{0}=-0.31$ and $z_{\mathrm{H}}=0.15_{5}$. The coordinates $y^{\prime}$ and $z^{\prime}$ were calculated from equations similar to (1). A certain radial distance around the oxygen atom had to be selected; in this work a distance of $4 \AA$ has been used, and all atoms having a value $d_{i}$ less than $4 \AA$ were included in the equations for $x^{\prime}, y^{\prime}$ and $z^{\prime}$.

Calculation of the distance between the oxygen atom and the point $x^{\prime}, y^{\prime}, z^{\prime}$ suggested that the above procedure is, as expected, not quite exact. It has been assumed that the position found is correct in direction, with respect to the oxygen atom.

A model for the water molecule has been chosen from the compilation of data given by Chidambaram (1962). The $\mathrm{O}-\mathrm{H}$ bond distance is taken as $0.99 \AA$ and the angle $\mathrm{H}-\mathrm{O}-\mathrm{H}$ as $104.5^{\circ}$, from which the distance from the oxygen to the positive end of the water molecule dipole is $0.6 \AA$ and the interproton distance is $1.6 \AA$.

From this data, a number of hydrogen-atom positions were generated in steps, $\psi$, of $22.5^{\circ}$, all lying on a circle centre $x^{\prime}, y^{\prime}, z^{\prime}$ (corrected) of radius $0.8 \AA$, such that all $\mathrm{O}-\mathrm{H}$ distances generated were $0.99 \AA$. Madelung constants were calculated for the structure using the method of Bertaut (1952) as elaborated by Templeton (1955) and by Jones and Templeton (1956), for a spherical charge distribution, Equation (2), using sets of the hydrogen-atom positions generated, together with the known positions of the remaining atoms:

$$
A(L)=\frac{(g-Q) L \sum_{j}\left(z_{j}\right)^{2}}{R N}-\frac{\pi R^{2} L \sum_{\mathbf{h}}\left|F_{\mathbf{h}}\right|^{2} \varphi_{\mathbf{h}} w_{\mathbf{h}}}{N V_{0}}
$$


$g=26 / 35 ; Q$ is a series-termination correction, which is 0.0003 when $\alpha_{\max }$ is $2 \pi$;

$L$ is a standard distance,

$R$ an arbitrary distance less than half the nearest-neighbour distance, $N$ the number of formula weights per unit cell,

$V_{c}$ the volume of the unit cell and

$\mathrm{h}$ a reciprocal vector;

$F_{\mathbf{h}}=\sum_{j} z_{j} \exp \left(2 \pi i \mathbf{h} \cdot \mathbf{x}_{j}\right)$;

$\varphi_{\mathbf{h}}=288(\alpha \sin \alpha+2 \cos \alpha-2)^{2} \alpha^{-10}$;

$\alpha=2 \pi|\mathbf{h}| R$ and

$w_{\mathbf{h}}$ is the multiplicity of $F_{\mathbf{h}}$.

In these calculations, $L=0.99, R=0.495 L$ and $\alpha_{\max }=2 \pi$. The extent of the summation in Equation (2) is determined by $\alpha_{\max }$ and $R$; for the values stated, adequate 'convergence was obtained.

\section{Results}

For the two hydrates studied, the positions of the hydrogen atoms which led to minimum-energy structures were clearly indicated.

(a) Barium chloride dihydrate

Table 1 lists data relevant to the approximate coordinates of the positive end of the water-molecule dipole, for the two oxygen atoms in the asymmetric unit. Fig. 1 shows the variation of the Madelung constant $A(L)$ with $\psi$. The value of $\psi$ at maximum $A(L)$ led to the

Table 1. Barium chloride dihydrate

\begin{tabular}{c|c|c|c|c|c}
\hline $\begin{array}{c}\text { Oxygen } \\
\text { atom }\end{array}$ & $\begin{array}{c}\text { Number } i \text { of } \\
\text { neighbours }\end{array}$ & $x^{\prime}$ & $y^{\prime}$ & $z^{\prime}$ & $d\left(\mathrm{O}-x^{\prime} y^{\prime} z^{\prime}\right)$ \\
\hline $\mathrm{O}_{1}$ & 11 & 0.416 & 0.079 & 0.974 & $0.75 \AA$ \\
$\mathrm{O}_{2}$ & 9 & 0.183 & 0.113 & 0.606 & 0.82
\end{tabular}

Table 2. Barium chloride dihydrate

\begin{tabular}{c|c|c|c|c|c|c}
\hline & \multicolumn{3}{|c|}{ PadmanabHan et al. } & \multicolumn{3}{c}{ This work } \\
\cline { 2 - 7 } & $x$ & $y$ & $z$ & $x$ & $y$ & $z$ \\
\hline $\mathrm{H}_{11}$ & 0.3534 & 0.0616 & 0.8824 & 0.381 & 0.064 & 0.874 \\
$\mathrm{H}_{12}$ & 0.4756 & 0.1255 & 0.0402 & 0.440 & 0.119 & 0.061 \\
$\mathrm{H}_{21}$ & 0.0977 & 0.1368 & 0.5967 & 0.082 & 0.154 & 0.586 \\
$\mathrm{H}_{22}$ & 0.2466 & 0.0654 & 0.4877 & 0.294 & 0.091 & 0.573
\end{tabular}


coordinates listed in Table 2. The results are compared with the data of Padmanabhan, Busing and Levy (1963). With the exception of $z\left(H_{22}\right)$, the agreement is good.

\section{(b) Sodium bromide dihydrate}

A similar analysis was cairied out with sodium bromide dihydrate. Table 3 and Fig. 2 illustrate the results. Table 4 lists the coordinates of the hydrogen atoms and compares them with the data of VAN

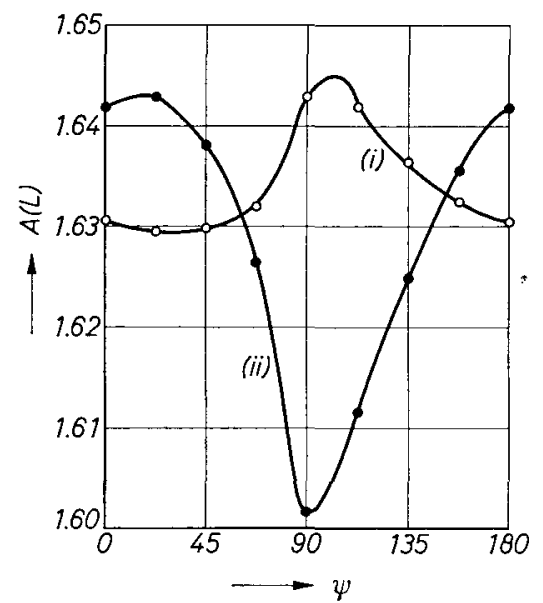

Fig. 1

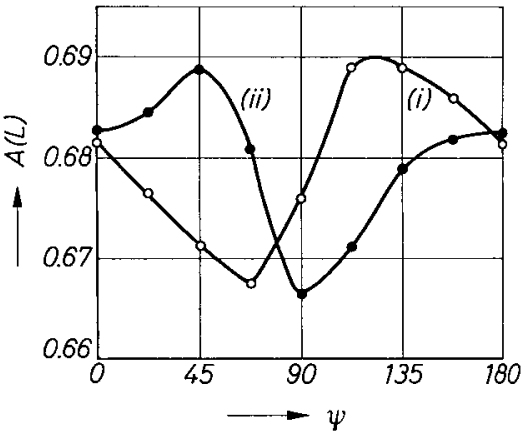

Fig. 2

Fig. 1. Variation of Madelung constant with hydrogen atom position. Barium chloride dihydrate. (i) $H_{11}$ and $H_{12}$ varying, with $H_{21}$ and $H_{22}$ fixed; (ii) $H_{21}$ and $\mathrm{H}_{22}$ varying, with $\mathrm{H}_{11}$ and $\mathrm{H}_{12}$ fixed

Fig. 2. Variation of Madelung constant with hydrogen atom positions. Sodium bromide dihydrate. (i) $H_{11}$ and $H_{12}$ varying, with $H_{21}$ and $H_{22}$ fixed; (ii) $H_{21}$ and $\mathrm{H}_{22}$ varying, with $\mathrm{H}_{11}$ and $\mathrm{H}_{12}$ fixed

Meerssche, Dereppe and Lobo (1962), obtained from a proton magnetic resonance study. In this case, the variations between the coordinates deduced by the two methods are larger.

Table 3. Sodium bromide dihydrate

\begin{tabular}{c|c|c|c|c|c}
\hline $\begin{array}{c}\text { Oxygen } \\
\text { atom }\end{array}$ & $\begin{array}{c}\text { Number } i \text { of } \\
\text { neighbours }\end{array}$ & $x^{\prime}$ & $y^{\prime}$ & $z^{\prime}$ & $d\left(\mathrm{O}-x^{\prime} y^{\prime} z^{\prime}\right)$ \\
\hline $\mathrm{O}_{1}$ & 9 & 0.196 & 0.029 & 0.684 & $\begin{array}{l}0.72 \AA \\
\mathrm{O}_{2}\end{array}$ \\
\hline 11 & 0.782 & 0.163 & 0.818 & 0.55
\end{tabular}


Table 4. Sodium bromide dihydrate

\begin{tabular}{l|c|c|c|c|c|c}
\hline & \multicolumn{2}{|c|}{ VAN Mefrssche et al. } & \multicolumn{3}{c}{ This work } \\
\cline { 2 - 7 } & $x$ & $y$ & $z$ & $x$ & $y$ & $z$ \\
\hline$H_{11}$ & 0.269 & 0.029 & 0.635 & 0.298 & 0.052 & 0.657 \\
$H_{12}$ & 0.129 & -0.017 & 0.765 & 0.124 & -0.001 & 0.744 \\
$H_{21}$ & 0.861 & 0.221 & 0.925 & 0.804 & 0.222 & 0.753 \\
$H_{22}$ & 0.741 & 0.098 & 0.792 & 0.772 & 0.101 & 0.882
\end{tabular}

\section{Discussion}

The results presented support the proposed method for the approximate location of hydrogen atoms in ionic hydrates. The idea of a minimum-energy structure is not new, but its application to the determination of hydrogen atom :coordinates has not been reported previously.

The x-ray data on sodium bromide dihydrate, reported by CuLot, Piret and van Meerssche (1962), was examined. The structure factor data was refined anisotropically to an $R$ value of $9.3 \%$. Difference Fourier sections were inconclusive in respect of hydrogen atoms; this was not unexpected. Eight maxima were found around each oxygen atom. Four of these maxima led to the approximate hydrogen positions listed in Table 5, using relevant stereochemical data.

The positions (ii) were easily eliminated from a consideration of Pauling's rules leaving positions (i) in fair agreement with data given in Table 4. Positions (iii) and (iv) both led to stereochemically unacceptable models for the water molecule. An interesting feature of the proposed method lies in the fact that the contribution of the hydrogen atoms to $F_{\mathbf{h}}$ in Equation (2) is one half that of the oxygen

Table 5. Sodium bromide dihydrate; Fourier studies

\begin{tabular}{c|c|c|c|c|c|c}
\hline & & $x$ & $y$ & $z$ & O-H & H-O-H \\
\hline (i) & $\mathrm{H}_{11}$ & 0.26 & 0.03 & 0.63 & $1.01 \AA$ & 104.8 \\
& $\mathrm{H}_{12}$ & 0.20 & 0.08 & 0.82 & 0.98 & 108.8 \\
(ii) & $\mathrm{H}_{11}$ & 0.43 & 0.03 & 0.92 & 1.07 & \\
& $\mathrm{H}_{12}$ & 0.18 & -0.04 & 0.85 & 1.07 & 104.5 \\
& & & 0.20 & 0.90 & 0.97 & \\
(iii) & $\mathrm{H}_{21}$ & 0.87 & 0.11 & 0.78 & 1.15 & 93.7 \\
& $\mathrm{H}_{22}$ & 0.75 & 0.75 & 0.97 & \\
(iv) & $\mathrm{H}_{21}$ & 0.87 & 0.20 & 0.90 & 0.89 & 84.0
\end{tabular}


atoms and about one sixth that of the sodium and of the bromine atoms, at all values of $\mathbf{h}$. This contrasts with the conventional $\mathbf{x}$-ray crystallographic methods, in which the contribution of the hydrogen atoms are comparable with background scattering, in the presence of moderately heavy atoms such as sodium or bromine.

If the idea of a minimum-energy structure is used, then, since about $90 \%$ of the lattice energy is electrostatic in nature, the lowest energy corresponds to the largest value of $A(L)$. This condition may be obtained by minimizing the second term on the right-hand side of Equation (2) with respect to small variations in the uncertain coordinates of the hydrogen atoms, once the location of the other atoms in the crystal structure is known.

The process of minimization corresponds to a normal crystallographic least-squares calculation in which $\left|F_{\mathrm{o}}\right|=B=0$, for all $\mathrm{h}$, and in which $\left|F_{\mathrm{c}}\right|-\left|F_{\mathrm{h}}\right|$ of Equation (2) - is weighted by the term $\varphi_{\mathrm{h}} w_{\mathrm{h}} ; B$ is an isotropic temperature factor. Further work will be concerned with this calculation and with improvements of the general method proposed.

The Madelung constants for a distance $L=0.99 \AA$ are $1.64_{4}$ for barium chloride dihydrate and $0.689_{4}$ for sodium bromide dihydrate; the electrostatic contributions to the lattice energies are thus $\mathbf{5 5 2}$ $\mathrm{kcal} / \mathrm{mole}$ and $231 \mathrm{kcal} / \mathrm{mole}$ respectively.

\section{References}

F. Bertaut (1952), L'énergie électrostatique de réseaux ioniques. J. physique radium $13,499-505$.

R. Chidambaram (1962), Structure of the hydrogen-bonded water molecule in crystals. J. Chem. Physics 36, 2361-2365.

J. P. Culot, P. Piret and M. van Meerssche (1962), Structure de $\mathrm{NaBr} \cdot 2 \mathrm{H}_{2} \mathrm{O}$. Bull. Soc. franç. Minér. Cristallogr. 85, 282-289.

R. E. Jones and D. H. Temple'ton (1956), Optimum atomic shape for Bertaut series. J. Chem. Physics 23, 1062-1063.

M. F. C. LADD and W. H. LeE (1965), The thermodynamies of erystalline hydrates. J. Physic. Chem. 69, 1840-1843.

M. van Meerssche, J.-M. Dereppe and P. W. Lobo (1962), Structure protonique de $\mathrm{NaBr} \cdot 2 \mathrm{H}_{2} \mathrm{O}$. Bull. Soc. franç. Minér. Cristallogr. 85, 290-292.

V. M. Padmanabhan, W. R. Busnng and H. A. Levy (1963), A single-crystal neutron-diffraction study of $\mathrm{BaCl}_{2} \cdot 2 \mathrm{H}_{2} \mathrm{O}$. Acta Crystallogr. (Rome Abs. 4,19), 16, A26.

A. A. Silvidi and J. W. McGrath (1960), Proton magnetic resonance study of the structure of barium chloride dihydrate. J. Chem. Physics 32, 924-926.

D. H. Templeton (1955), Rate of convergence of Madelung series by the method of Bertaut. J. Chem. Physies 23, 1629-1630. 